\title{
¿Quién parte y reparte? Análisis de la disposición urbana en la Cartago fenicia
}

\section{Who gets the lion's share? Analysis of the urban layout in the phoenician Carthage}

\author{
Iván Fumadó Ortega \\ FECYT. Zentrale des Deutschen Archäologischen Instituts Berlin
}

\section{RESUMEN}

En este artículo quiero llamar la atención sobre la significativa regularidad arquitectónica que caracteriza los restos arqueológicos prerromanos registrados en Cartago. Pese a haber sido repetidas veces interpretados desde un prejuicio lógico-espacial, estos datos permiten proponer que la fundación tiria se implantố en la península cartaginesa según un modelo que, estando mejor documentado en las colonias arcaicas griegas de Sicilia, ha sido denominado per strigas por la historiografía arqueológica.

Para defender esta tesis señalaré qué restos arquitectónicos le sirven de base material, con especial atención a los hallados bajo el cruce entre el decumano máximo y el cardo x este, e intentaré sintetizar el estado de la cuestión actual sobre la forma urbana de la Cartago fenicia. A continuación repasaré algunos ejemplos de segmentación ortogonal de espacios urbanos documentados en el Próximo Oriente antiguo. Ello nos ayudará a suponer cuál habría sido el contexto técnico y práctico en que vivieron las sociedades fenicias de los siglos IX-VIII a.C. y, más concretamente, el contexto sociopolítico de los fundadores de Cartago. Por último y a la luz de estos elementos, presentaré una propuesta de reconstrucción de la forma urbana de la Cartago fenicia.

\section{SUMMARY}

In this paper I would like to highlight the significant architectural regularity which characterizes the pre-Roman archeological remains registered in Carthage. Despite having been repeatedly interpreted from a preconceived logical and spatial point of view, these remains allow us to set out that the Tyrian foundation was established in the Carthaginian peninsula according to a model that is referred to as per strigas in archaeological literature because it was documented better at the Archaic Greek colonies in Sicily.

To defend this idea, I will indicate which architectonic remains make up its material basic, paying special attention to the remains found underneath the crossroads of the decumanus maximus and the cardo $\mathrm{x}$-east, and I will try to summarize the state of the current issue on the urban shape of Phoenician Carthage. I will then go over several documentated examples of orthogonal land division in urban spaces from the Ancient Near East. This information will provide insight on the possible technical and practical context of Phoenician societies in the $9^{\text {th }}$ and $8^{\text {th }}$ centuries $\mathrm{BC}$ and, more specifically, the socio-political context of the Carthaginian founders. Finally, in light of these elements, I will put forward a proposal of a reconstruction of the urban layout of Phoenician Carthage as a whole.

PALABRAS CLAVES: Morfología urbana, urbanismo, ciudad antigua, colonia arcaica.

KEY WORDS: Urban morphology, Urban development, Ancient city, Archaic colonies.

LA EVIDENCIA ARQUEOLÓGICA: EL (DES) INTERÉS POR LA ORIENTACIÓN DE LAS ESTRUCTURAS ARQUITECTÓNICAS

La arqueología mediterránea se desarrolló durante el siglo XIX y principios del XX en un contexto dominado por los paradigmas de la arqueología colonial (Dietler 2005), que, mediatizando la investigación sobre las sociedades fenicio-punicas (Van Dommelen 1998: 17-22), se concretó en relación con la arqueología cartaginesa en la formación de un prejuicio lógico-espacial (Fumadó Ortega 2010: 10-11). Han sido múltiples las consecuencias que este prejuicio ha provocado en el desarrollo de la arqueología feniciopúnica desde principios del siglo XX (cf. Vella 1996). Una de las principales para Cartago fue que se propagó, como lugar común, la idea de que no se hallarían en dicho yacimiento restos arquitectónicos relevantes, ya que la sociedad cartaginesa no habría desarrollado las capacidades técnicas ni artísticas necesarias para producir ni la gran arquitectura ni el urbanismo de las ciudades griegas o romanas (cf. Bonnet y Krings 2006: 40). Si acaso alguna vez existió algo similar, estos restos habrían sido destruidos por los romanos durante el asedio y toma del 146 a.C. y, posteriormente, durante la construcción de la Colonia Iulia. 
Sin embargo, son múltiples las evidencias que apuntan a que la Cartago arcaica se construyó como una ciudad per strigas (cf. Hoepfner y Schwandner 1994: 1-10). A continuación repasaré este registro material según el orden cronológico en que fue arqueológicamente documentado. Prestaré especial atención a la orientación que presentan las estructuras arquitectónicas, coincidentes entre sí en la mayoría de los casos, como veremos.

En el contexto académico de la segunda mitad del siglo XIX, quizá el orientalismo y clasicismo imperantes en las universidades europeas (Saïd 1978; Marchand 1996) hicieron sentir a los investigadores del mundo fenicio la necesidad de excavar en los yacimientos que la Historia señalaba como principales. Tras la desilusión que supuso la Mission de Phénicie acometida entre 1860 y 1861, Cartago se perfiló como el único lugar en donde todavía se podía esperar dar con la arquitectura monumental fenicio-púnica.

La muralla acaparó gran parte de las expectativas, ya que era descrita por las fuentes como formidable e insuperable (App. Pun. 95; Plb. 1.18. 8; 1.38.7; D.S. 23.8.1; Str. 2.5.33; 6.4.2; 12.8.11). Si Charles Ernest Beulé (1861: 42-66) quiso ver las murallas púnicas allí donde incluso Nathan Davis (1861: 372374) veía únicamente un muro de contención, Charles Tissot se propuso aclarar definitivamente el sistema defensivo de la Cartago púnica (Tissot 1884: 569588; Reinach y Babelon 1886: 5), con un proyecto arqueológico que Salomon Reinach y Ernest Babelon intentaron aplicar a partir de 1883. Problemas económicos limitaron sus áreas de actuación a los solares que no coincidían con el hipotético trazado de la muralla, por lo que los savants fijaron sus esperanzas en dar, al menos, con los palacios de la aristocracia cartaginesa, probablemente influidos por las reconstrucciones propuestas por William Turner y descritas por Gustav Flaubert. En este intento se vaciaron tres grandes trincheras en la primavera de 1884: la primera de ellas (Fig. 1.27) no profundizó lo suficiente como para hallar restos anteriores al 146 a.C., pero sí la segunda, de $56 \mathrm{~m}$ de longitud por 13 $\mathrm{m}$ de anchura y $9 \mathrm{~m}$ de profundidad, excavada en Feddan-el-Behim (Fig. 1.6), así como la tercera, la más grande de todas, con $135 \mathrm{~m}$ de longitud, abierta entre Bir Massouda y Bir ez-Zrig (Fig. 1.15).

Es importante destacar que en esta intervención se halló una superposición estratigráfica de viviendas prerromanas, las primeras púnicas jamás excavadas en todo el Mediterráneo, que habrían permitido seguir su evolución desde las fases más antiguas de la ciudad hasta su destrucción en el 146 a.C. Además, destaca el hecho de que estos restos siguen solo tres orientaciones (Fumadó Ortega en prensa): la primera de ellas, situada en los estratos más profundos, está compuesta por muros orientados del mismo modo que los excavados más recientemente bajo el cruce del decumano máximo con el cardo x este (Niemeyer $e t$ alii 2007) ${ }^{1}$; la segunda, en los estratos intermedios, la forman estructuras con una dirección coincidente a la documentada en el Barrio de Aníbal (Fig. 1.24) (Lancel 1982) ${ }^{2}$; la tercera y última, la más superficial, respeta la alineación del Barrio de Magón (fig. 1.21) y de la Colonia Iulia (Rakob 1991) ${ }^{3}$. Pese a la enorme trascendencia que habría tenido una adecuada interpretación de este registro, la escasa monumentalidad de los restos que sobrevivieron a un proceso de excavación típico para el siglo XIX supuso una desilusión para quienes buscaban grandes residencias palaciales. La atención que los propios excavadores prestaron a estos resultados a partir de entonces fue prácticamente nula (cf. Babelon 1896).

Los arqueólogos que posteriormente excavaron en Cartago, principalmente Alfred Louis Delattre (Freed 2001) y Paul Gauckler (1915), pero también Jean Vernaz (1887), Alfred Merlin (1909; 1912; 1918), Louis Drappier (1911) o René Cagnat (1909), pasaron a interesarse por las necrópolis, ricas al menos en ajuares fácilmente musealizables. Solo de forma marginal se dio cuenta de algún que otro hallazgo relativo al espacio de hábitat púnico (Delattre 1898: 146) cuya planimetría revelaba la misma orientación que las viviendas excavadas por Salomon Reinach y Ernest Babelon (Renault 1913: 33 fig. 21). En otras ocasiones se hallaron, en zonas previamente empleadas como necrópolis, cisternas a bagnarola con la misma coincidente orientación a $45^{\circ}$, como en la zona de Dermech (Fig. 1.2) (Gauckler 1915; Bénichou-Safar 1982: fig. 22; Lancel 1990: 27 y ss.) o en las primeras pendientes de la colina de Bordj Djedid (Fig. 1.1) (Poinssot y Lantier 1927: lám. 18), así como nuevas viviendas prerromanas en el terreno Grosjean (fig. 1.5) (Cintas 1970: 441; 1976: 124) o en el terreno Clariond (Fig. 1.14) (Cintas 1976: 125; Fantar 1993: 135), con los típicos elementos de la arquitectura doméstica púnica: pasillo de ingreso, patio central con pozo, sala de baño, etc., al parecer siempre con la misma orientación, sin que este hecho llamase particularmente la atención: La vérité es qu'il en reste à peu près rien de la citè punique (Cagnat 1909: 9) fue una frase compartida

\footnotetext{
${ }^{1}$ Esto es, muros que apuntan a $45^{\circ}$ al noreste y otros, perpendiculares, a $45^{\circ}$ al noroeste.

${ }^{2}$ Es decir, con muros orientados a $63^{\circ}$ al noreste y otros, perpendiculares, a $27^{\circ}$ al noroeste.

${ }^{3}$ Esto es, con estructuras arquitectónicas que siguen una dirección de $30^{\circ}$ al noreste y otros, perpendiculares, de $60^{\circ}$ al noroeste.
} 
hasta bien entrada la década de los años 70 del pasado siglo (Cintas 1976: 124; Tlatli 1978: 57).

Gracias a la campaña internacional de la UNESCO se hallaron restos arquitectónicos prerromanos con la misma alineación en otras ocho intervenciones. Varias de ellas fueron acometidas por el equipo del Deutsches Archäologisches Institut, como la del terreno Ben Ayed (Fig. 1.9). Aquí, gracias a la oportunidad que brindaba la construcción de una residencia privada, se pudo excavar hasta niveles naturales. Entre las aportaciones más relevantes de esta intervención se cuentan la documentación de una superposición de viviendas prerromanas, desde la segunda mitad del siglo VIII a.C. hasta el 146 a.C., orientadas a $45^{\circ}$ (Rakob 1984: lám. 8).

Otra intervención de este equipo fue la excavación de una calle romana, el decumano IV sur (fig. 1.17), en donde se pudo documentar una interesante sucesión de estructuras arquitectónicas. La más profunda de ellas era un fragmento de terrazzo del siglo IV a.C. en el que se podía apreciar la impronta del muro que se le apoyó encima, que seguía la alineación a $45^{\circ}$ (Rakob 1989: fig. 20). Cabe mencionar, igualmente, la estructura hallada al norte de las Lagunas de Salammbô (Fig. 1.18) que, con la misma orientación que los restos anteriores, fue interpretada como cimiento de uno de los bastiones de la muralla marítima (Rakob 1989: lám. 149, 1).

En el marco institucional de la campaña de la UNESCO también se llevó a cabo el programa Sewer Project, que debía realizar el seguimiento de las obras de instalación de canalizaciones subterráneas en la moderna banlieue Carthage. Como resultado, entre otros, se pudieron documentar dos fragmentos de muro, ambos bajo estratos augusteos, que diferían de estos en dirección y apuntaban a $45^{\circ}$ hacia el noreste, tanto en la rue Augustin (Fig. 1.4) (Ellis 1988) como en la Av. Pline (Fig. 1.16) (Ellis 1989: 19).

Otras intervenciones no programadas pudieron llevarse a cabo en el yacimiento con resultados similares, al menos en cuanto se refiere al hallazgo de restos arquitectónicos prerromanos orientados a $45^{\circ}$. Así fue en la rue Président Kennedy (Fig. 1.10), en donde se documentó una cisterna a bagnarola (Lancel 1994: 142-146), dos más en la ladera este de la Byrsa (Fig. 1.12) (Lancel 2002: 19-22 y 121-122), y finalmente en la rue Astarté (Fig. 1.11), en donde pudo documentarse casi integramente una vivienda de los siglos III-II a.C. (Chelbi 1984; 2004).

Tras la campaña internacional de la UNESCO los equipos que han seguido trabajando en el yacimiento han seguido encontrado estructuras arquitectónicas prerromanas orientadas a $45^{\circ}$. Es el caso del equipo del Deutsches Archäologisches Institut que comenzó, a partir de 1990, la excavación de la rue Ibn Chabâat (Fig. 1.7) (Rakob 1991; 1997) ${ }^{4}$. Aquí se hallaron los potentes cimientos de las tabernae tardorromanas, sobre las que se construyó en época bizantina un edificio sacro de planta circular (Rakob 1995: 440-461). Estas estructuras se apoyaban sobre los grandes bloques rectangulares de un edificio más antiguo, interpretado por Friedrich Rakob (1995: 420-427) como un templo púnico activo al menos desde la segunda mitad del siglo III a.C., al que se asociaron las más de 5.000 improntas en sellos de arcilla hallados en las proximidades (Rakob 1987: 10-214). En una reinterpretación posterior, Roald Docter (2003: 122-128) ha propuesto que el gran muro de contención en el que se apoyaba este conjunto fue originalmente un tramo de la muralla arcaica de casamatas. Igualmente, dada la gran cantidad de cenizas, escorias y otros residuos de actividades metalúrgicas hallados en la zona sur de la excavación, se ha propuesto aquí la existencia de un barrio industrial análogo al documentado para las mismas fechas en la playa (Fig. 1.20) (Rakob 2002: 26-27).

Otros equipos han llevando a cabo desde 1988 nuevas intervenciones en la zona de Bir Massouda (Fig. 1.13). Aquí, bajo los estratos romanos, el Institut National du Patrimoine y la Universiteit Gent han hallado, además de otro tramo de la muralla arcaica de casamatas (Docter et alii 2006: 41) que permite precisar aún más los límites de la ciudad fenicia (Docter et alii 2003: 45 y ss.), una serie de viviendas púnicas construidas a partir del siglo $\mathrm{V}$ a.C., orientadas aproximadamente a $45^{\circ}$ y dotadas de estancias para el baño, letrinas y mosaicos. Este grupo de hábitats se alzaba sobre una serie de instalaciones dedicadas al trabajo metalúrgico a gran escala (Docter et alii 2006: 63-66) construido, a su vez, en el siglo VII a.C. sobre los restos de la necrópolis más antigua documentada hasta el momento en Cartago (Chelbi et alii 2007: 222 y ss).

\section{LAS VIVIENDAS FENICIAS HALLADAS BAJO EL DECUMANO MÁXIMO Y EL CARDO X ESTE}

Quizá los restos más interesantes para este artículo son los de las casas excavadas por la Universität Hamburg (Niemeyer et alii 2007) bajo el cruce del decumano máximo con el cardo X este (Fig. 1.8). La intervención, acometida entre 1986 y 1995, registró

\footnotetext{
${ }^{4}$ En este punto el Deutsches Archäologisches Institut ha retomado sus excavaciones desde 2009 bajo la dirección de Heimo Dolenz y Christof Flügel.
} 
otra secuencia completa de un barrio residencial desde su construcción a mediados del siglo VIII a.C. hasta su destrucción en el 146 a.C. El registro permite estudiar la vida constructiva de estas viviendas con nuevos niveles de detalle. Se pueden distinguir así las diversas influencias siriopalestinas, desde la aportación al Mediterráneo central del siglo VIII a.C. de la planta arquitectónica del tipo four room house, hasta la introducción del opus africanum a mediados del siglo VI a.C. (Niemeyer et alii 2007: 95-99). También resulta evidente y significativa la imposición desde el siglo VIII a.C. de un diseño ortogonal y regular del espacio urbano, que fue respetado hasta el siglo II a.C.

Desde la fase IIa (740-725 a.C.) se documentan seis viviendas cuyos límites perimetrales, al margen de las reestructuraciones internas y funcionales sufridas por la casa 1, no sufrieron modificaciones sustanciales hasta su destrucción definitiva ${ }^{5}$. Este hecho resulta difícilmente explicable sin admitir la contribución decisiva de una autoridad pública, que haya velado por el respeto hacia los límites catastrales durante todas las frecuentes remodelaciones interiores que se llevaron a cabo en estas viviendas.

La orientación de los restos estructurales más antiguos hallados en este punto revelan, no obstante, una cierta disparidad. Los restos de muro de tres de las cuatro estancias documentadas en la fase I (760-740 a.C.) (Niemeyer et alii 2007: 59-67 plano 1), mantienen una diferencia de $10^{\circ}$ respecto a la cuarta. Esta última, sin embargo, resulta perpendicular, y por lo tanto concordante, con uno de los muros más antiguos documentados recientemente el área de Bir Massouda, a unos $100 \mathrm{~m}$ de distancia hacia el sur (Docter et alii 2006: 42 fig. 7).

Estos elementos, que suponen las más antiguas evidencias arquitectónicas halladas por el momento en Cartago y que carecen de una clara orientación común, podrían corresponderse con los restos de una primera fase de instalación y reunión de población varia y dispersa, ya indicada por las fuentes (Just. 18.4-5). Durante este primer periodo, de duración incierta (Gras 2002: 184-186), probablemente faltó tanto una legislación urbanística eficaz como siquiera un proyecto común de crecimiento. Consecuentemente cada individuo que dispusiera de derechos suficientes para ello, debió de construirse una morada según sus propios recursos y posibilidades. La yuxtaposición de este tipo de construcciones produce un crecimiento

\footnotetext{
${ }^{5}$ Se puede considerar una excepción el estrato VIIIa, que muestra una importante reestructuración urbana durante la primera mitad del s. II a.C., pero que, de todos modos, respetó la orientación de muchos de los muros perimetrales de las casas preexistentes (Niemeyer et alii 2007: 155-169 plano 11).
}

urbano que no excluye, sin embargo, el respeto de ciertas normas consuetudinarias basadas en la tradición cultural de estos primeros habitantes.

Esta situación cambió durante la segunda mitad del siglo VIII a.C., para cuando se puede defender la puesta en práctica en Cartago de una operación de regularización catastral. Debió de ser en este contexto en el que se derribaron los edificios que guardaban orientaciones discordantes, como las viviendas más antiguas halladas en la rue Ibn Chabâat, y se pasó a construir según una orientación uniforme marcada por un catastro. Así se explica por qué el resto de elementos arquitectónicos cartagineses, concretamente todos los arcaicos y gran parte de los posteriores, siguen mayoritariamente la misma orientación (Fig. 1).

Esta primera gran reforma urbana queda reflejada en la fase IIa (740-725 a.C.) de la excavación de la Universität Hamburg, donde la casa que seguía una orientación diversa fue arrasada y reconstruida según las dimensiones y la alineación del resto. Aunque las parcelas de terreno, con medidas regularizadas, no fueron completamente edificadas hasta la fase IVa (675-645 a.C.), lo hicieron entonces respetando los límites que parecen haber sido ya fijados desde la fase IIa. Así, se puede asumir que las casas que daban a la calle este se construyeron con base en la parcela asignada en el siglo VIII a.C., de $12 \mathrm{~m}$ de longitud por $8 \mathrm{~m}$ de anchura, ofreciendo un área total de unos $100 \mathrm{~m}^{2}$. Dichas parcelas se complementaban con otras, algo más reducidas, de $9 \mathrm{~m}$ de longitud por $8 \mathrm{~m}$ de anchura, es decir, con un área total aproximada de 72 $\mathrm{m}^{2}$ (Niemeyer et alii 2007: 188-195).

Estas viviendas se adosaron unas a otras por su parte posterior formando una pareja de $21 \mathrm{~m}$ de longitud, si bien las dimensiones exactas permanecen inciertas debido a que el límite oeste de la casa 2 quedó fuera del área excavada. Además, estas casas emparejadas se adosaban a otras, tanto a derecha como a izquier$\mathrm{da}$, formando de este modo las manzanas estrechas y alargadas que la investigación moderna denomina strigas (Hoepfner y Schwandner 1994: 1-10). Dichas manzanas se disponen separadas unas de otras, a este y oeste, por medio de estrechas callejuelas que la historiografía sobre la ciudad antigua griega conoce como stenópoi. Para las calles en este sector de Cartago se ha propuesto una anchura de 3 a 2,5 $\mathrm{m}$ (Niemeyer et alii 2007: 180-188). Al traducir las medidas documentadas a codos púnicos (Barresi 2007), se evidencian una serie de coincidencias metrológicas ${ }^{6}$ provocadas por el uso

\footnotetext{
La relación entre la anchura de los stenópoi y la de las viviendas de la calle oeste sería así de $1 / 3$; de $2 / 3$ sería la relación entre la longitud y la anchura de las casas de la calle este; $1 / 4$, entre la longitud de estas casas y la anchura de las
} 


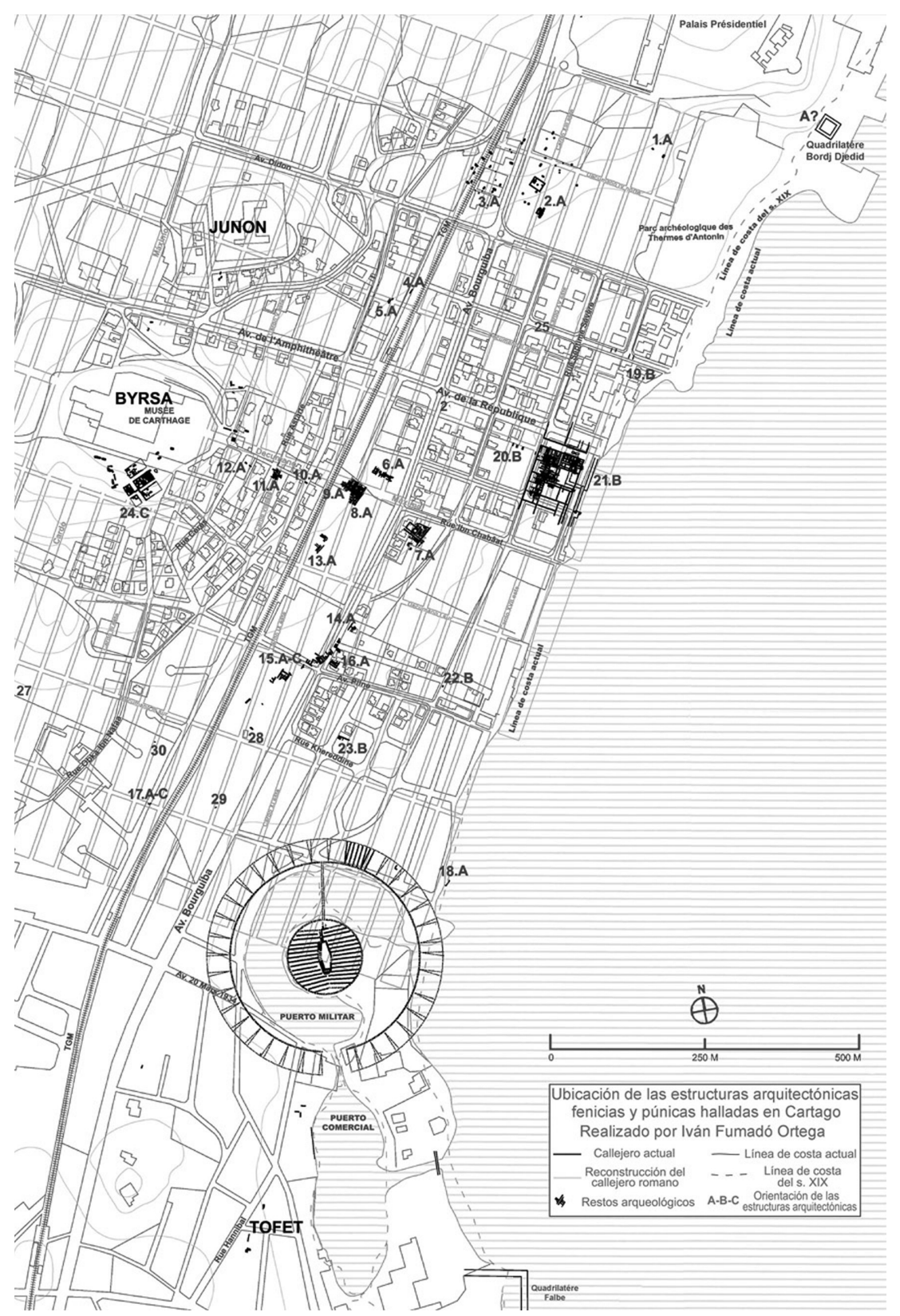

Figura 1. Plano de la actual banlieue Carthage. En negrita figuran las estructuras arquitectónicas prerromanas. Las letras indican la orientación que presentan dichas estructuras (A: según las viviendas fenicias halladas bajo el decumano máximo; B: según el Barrio de Magón y la colonia Iulia; C: según el Barrio de Aníbal). Los números corresponden a las áreas de excavación mencionadas en el texto: 1. Ladera sur de Bordj Djedid (Poinssot y Lantier 1927); 2. Dermech (Gauckler 1915); 3. Doü̈mes-Dermech (Delattre 1897); 4. Rue Augustin (Ellis 1988$) ; 5$. Terreno Grosjean (Cintas 1970: 441; 1976: 124); 6. Feddan el-Behim (Reinach y Babelon 1886); 7. Rue Ibn Chabâat (Rakob 1991; 1999 ); 8. Cruce entre el decumano máximo y el cardo X este (Niemeyer et alii 2007); 9. Terreno Ben Ayed (Rakob 1984); 10. Rue Président Kennedy (Lancel 1994: 142-146); 11. Rue Astarté (Chelbi 1984a; 2004); 12. Ladera este de la Byrsa (Lancel 2002: 19-22, 121-122); 13. Bir Massouda (Docter et alii 2003; 2006); 14. Terreno Clariond (Cintas 1976: 125; Fantar 1993: 135); 15. Bir ez-Zrig (Reinach y Babelon 1886); 16. Av. Pline (Ellis 1989); 17. Sondeo en el decumano IV sur (Rakob 1989); 18. Playa al norte del Puerto Circular (Rakob 1987); 19. Rue Sophonisbe (Ellis 1988); 20. Rue Septime Sévère (Rakob 1989); 21. Barrio de Magón (Rakob 1991); 22. Rue Taieb Mehiri (Ellis 1988); 23. Rue Baal Hammon (Ellis 1989); 24. Barrio de Aníbal (Lancel 1982). 25. Rue Sophonisbe (Ellis 1988); 26. Terreno Fourti (Chelbi 1984b; 2004); 27. El Goulla (Reinach y Babelon 1886); 28. Basílica Cartagenna (Rakob 1989: 189); 29. Sondeo en el cardo IX este (Rakob 1989: 190-192); 30. Sondeo en el cardo VI este (Rakob 1989: 193-194); Diseñado por el autor. 
pragmático del sistema sexagesimal tradicionalmente empleado en las construcciones del Levante mediterráneo arcaico (Fig. 2). Más adelante veremos que esta disposición de casas y calles encuentra paralelos en el Mediterráneo central de los siglos VIII-VI a.C. (Gras 2002: 189-191; Mertens 2006: 63-89).

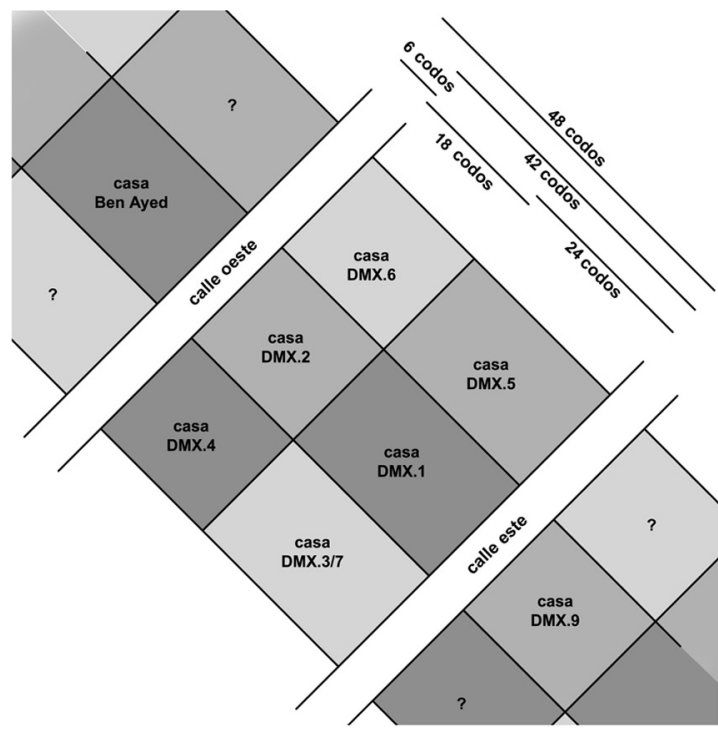

Figura 2. Hipótesis metrológica sobre las manzanas arcaicas de Cartago, calculada según un codo fenicio de $50-51 \mathrm{~cm}$. Diseñada por el autor.

\section{LECTURAS DE LA MORFOLOGÍA URBANA DE CARTAGO}

A partir de estos datos, junto a los correspondientes a las fases postarcaicas, se ha iniciado en las últimas décadas un debate sobre la forma de la ciudad. A Serge Lancel (1984) corresponde el mérito de haber presentado por primera vez una periodización del desarrollo urbano cartaginés articulada en tres fases, ahondando en una hipótesis esbozada por Pierre Cintas (1976: 124-126). Según esta, la fundación fenicia habría estado caracterizada por la coexistencia de dos núcleos urbanos diversos que siguieron desarrollos igualmente diversos. El primero de ellos debería de ubicarse en la cima de la Byrsa, identificada con la colina que actualmente lleva este nombre. Este núcleo de hábitat se habría extendido adaptándose a la difícil orografía del promontorio adoptando una forma en abanico (Lancel 1994: 136). Este urbanismo poligonal se ha documentado arqueológicamente en las laderas

calles, y $1 / 2$ entre la longitud de dichas casas y la anchura total de la striga. 1/8 sería por último la relación entre la anchura de las calles y la de las strigas (Fig. 2). de la Byrsa, tanto gracias a las excavaciones antiguas (Saumagne 1929; 1933; Lancel 1979: 13-58) como a las modernas (Chelbi 1984; 2004; Gerner Hansen 2002), siendo el Barrio de Aníbal (Lancel 1994: 149164) parte de este registro. Aquí se han identificado hasta siete grupos de estructuras arquitectónicas con orientaciones diversas, virando entre ellas aproximadamente unos $22^{\circ}$ (Lancel 1982: 376-378 fig. 607). Sin embargo, ninguno de estos elementos puede adscribirse cronológicamente a la fase arcaica (Ladjimi Sebaï 2003).

El segundo núcleo de hábitat habría crecido en paralelo a la costa, ocupando la petite plaine ${ }^{7}$ rodeada por las colinas de Bordj Djedid, Odeon, Juno y Byrsa por un lado, en donde las necrópolis representan un límite claro, y por el otro, por la playa. Aquí, al contrario que en la Byrsa, Serge Lancel (1994: 54) reconoció que se construyó de forma no anárquica, sino con la orientación natural que seguía la línea de costa (Lancel 1984: 48; 2000: 524).

Friedrich Rakob (1987: 334-337) compartió los puntos principales de esta hipótesis. No obstante, estaba convencido de la regularidad del esquema urbanístico aplicado por los cartagineses, si bien solo desde la construcción del Barrio de Magón en el siglo V a.C. (Rakob 1985: fig. 3). Varios investigadores tunecinos se han mostrado convencidos de que esta regularidad debió de existir también en el periodo arcaico (Fantar 1993: II, 174-178; Ben Younés 1995: 824-826), si bien no han llegado a presentar una propuesta arqueológica concreta. Por su parte, las últimas excavaciones publicadas no se han pronunciado sobre la forma conjunta de la ciudad (Niemeyer et alii 2007: 52).

Así, la investigación cartaginesa ha entrado en el nuevo siglo con cuestiones básicas todavía abiertas, entre ellas, el estudio de su morfología urbana. A pesar de las preocupaciones cartográficas asumidas por varios investigadores, desde Christian Tuxen Falbe hasta Friedrich Rakob (cf. Debergh 1991), todavía no se ha cumplido uno de los primeros requisitos de la investigación científica en un yacimiento arqueológico, es decir, la elaboración de una planimetría del conjunto a una escala suficiente (Clermont-Gennau 1896: 439-444).

La compleja y dilatada historia de la investigación en Cartago ( $c f$. Fumadó Ortega 2009) no permite el mismo grado de precisión en la localización de todos los sondeos, algunos de los cuales fueron publicados

\footnotetext{
${ }^{7}$ A pesar del nombre utilizado por Serge Lancel (1982: 379) el espacio referido tiene $1,6 \mathrm{~km}$ de playa y ocupa un área total de aproximadamente 100 ha, si bien es cierto que en época arcaica el nivel del mar se encontró más elevado y, por tanto, la línea de costa se hallaría más hacia el interior de lo que se encuentra hoy en día (Paskoff et alii 1985).
} 
sin aportar los suficientes datos o incluso han quedado inéditos. No obstante, la documentación ya publicada es muy rica y permite la creación de una planimetría de conjunto ${ }^{8}$. Su observación consiente nuevas aportaciones al estado de la cuestión anteriormente resumido (Fumadó Ortega 2013a).

\section{PARCELACIÓN DE TERRENO URBANO EN EL PRÓXIMO ORIENTE ANTIGUO}

La parcelación de la tierra con base en un principio geométrico de regularidad debe ser entendida como una solución técnica simple frente a un problema complejo por sus posibles implicaciones políticas: la organización racional del territorio. Esta solución técnica pudo ser producto de un invento afortunado o, más probablemente, fruto de un largo proceso de aproximaciones sucesivas y errores corregidos, puesto en marcha en el contexto de formación de los primeros imperios mesopotámicos y nilóticos (Hdt. 2.109; Prokl. in Euc. 65-68). La arqueología tan solo ha podido documentar estas experiencias en unos pocos ejemplos de finales del III milenio a.C. y de principios del II, como en Haradum (Kepinski-Lecomte 1996: 192) o en El-Lahun (Kemp 1992: 190-202). Estos son, no obstante, suficientes para apreciar cómo dichos conjuntos arquitectónicos han sido concebidos sin lugar a dudas con base en principios geométricos ortogonales. Cabe señalar que, en los ejemplos más antiguos, se trata de asentamientos pensados para cubrir necesidades muy específicas estrechamente ligadas a las políticas imperiales, ya sean militares, como en el caso de las fortalezas nubias, u organizativos, como en el de las

\footnotetext{
${ }^{8}$ Se puede crear un documento electrónico de tipo CAD con la superposición en diferentes capas de varios documentos: por una parte, las planimetrías publicadas tras las excavaciones arqueológicas antiguas y modernas; por otra, la cartografía antigua realizada por Bordy en 1898 a escala 1/5.000; por otra, el plano catastral de la banlieue de 1956 realizado a escala 1/2.000; por otra, las diversas fotografías aéreas publicadas (Kelsey 1926: lám. 3; Lapeyre y Pellegrin 1950: lám. 6; Duval 1950: fig. 2; Ferron y Pinard 1955: lám. 1; Baradez 1958: figs. 10-14 y lám. 1; Ferron y Pinard 1961: láms. 2-3; Duval 1972: figs. 13-15; Hurst 1975: láms. 1-2; Yorke y Little 1975: fig. 3; Bénichou-Safar 1976: lám. A; Cintas 1976: láms. 4144A; Humphrey 1978: figs. 3, 21; Tlatli 1978: figs. 9, 11, 15; Lancel 1979: figs. 8, 15; Bénichou-Safar 1982: figs. 2, 8-10; Hurst y Roskham 1984: lám. 1; Rakob 1984: lám. 1; Lancel 1989a: figs. 8, 22; Lancel 1989b: fig. 1; Rakob 1991: láms. 2, 4; Rakob 1992: 30; Hurst 1992: 80; Stevens 1993: fig. 2; Bénichou-Safar 1995: figs. 2-4; Ennabli 1997: figs. 10, 55, 71; Hurst 1999: fig. 3; Gerner Hansen 2002: fig. 10; Panero 2008: figs. 1, 12), además de las ofrecidas por Google Earth. El resultado de la aplicación de diversas fuentes de información (fotografía antigua, imágenes de satélite, cartografía antigua y moderna y planimetrías arqueológicas) permite dibujar una planimetría general próxima a una escala 1/1.000.
}

llamadas ciudades de las pirámides (cf. Kemp 1992: $180-189$ y 209). Cuando dichas necesidades imperiales cambiaron, estos asentamientos quedaron abocados al abandono. No obstante, incluso si no podemos calificarlos de auténticas ciudades, estos yacimientos demuestran claramente la existencia en el Próximo Oriente antiguo de una serie de conocimientos y habilidades técnicas y topográficas, así como de un dominio de la geometría (George 2008: 405-412), suficientes como para acometer con éxito una parcelación sistemática del espacio ocupado por un asentamiento de grandes dimensiones.

La extensión y la forma de las ciudades orientales de la Edad del Bronce, como también de las griegas durante la Edad Oscura, son resultado de varios complejos procesos de agrupamiento y crecimiento demográfico. Estas lentas dinámicas poblacionales, inscritas en sus concretos sistemas de gobierno, raramente debieron de suscitar un problema político cuya solución pasase por la parcelación regular del territorio. Alguno de estos singulares casos pudo darse en aquellas ciudades que, a raíz de su destrucción por causas bélicas o naturales, debían ser reconstruidas de nuevo por entero. Solo en estas ocasiones fue posible, si bien no necesario, la aplicación de una subdivisión racional de los espacios, no ya en un campamento de soldados u obreros, sino en una auténtica ciudad. Entre dichos casos, el mejor documentado es por el momento el de la ciudad chipriota de Enkomi: aquí, tras el incendio de las 13 ha que ocupaba la ciudad, esta se reconstruyó con una nueva muralla ciclópea, santuarios monumentales y un nuevo callejero reticular. Éste estuvo organizado mediante una avenida principal que discurría por el centro la ciudad y por 10 calles perpendiculares que la cruzaban en ángulo recto, formando así 20 estrechas manzanas, de anchura regular y longitud variable (Schaeffer y Courtois 1971: lám. 4).

Son conocidos otros ejemplos ya durante la Edad del Hierro, como Smirne. Aquí, desde el inicio del siglo X a.C., aproximadamente 9 ha habían sido ocupadas por múltiples grupos de cabañas ovales y absidiales, que fueron siendo progresivamente sustituidas por edificios de planta rectangular de tipo megaron. Pero solo tras su destrucción violenta a principios del siglo VIII a.C. la ciudad fue reconstruida según una organización con base en ejes viarios rectilíneos y regulares (Greco y Torelli 1983: 125-128).

En este sentido, uno de los ejemplos más elocuentes en el Levante mediterráneo lo constituye la ciudad de Megiddo (Kempinski 1989), donde a finales del siglo X a.C. se podía observar un paisaje urbano caracterizado por fuertes contrastes: por una parte se alzaban grandes edificios públicos en el barrio aristocrático; por otra, 
el restante espacio amurallado estaba ocupado por un amasijo de viviendas yuxtapuestas sin elementos que estructuraran el suelo urbano. Solo tras la conquista asiria del 733 a.C. y la consecuente destrucción de la ciudad, esta fue reconstruida mediante una red de calles estrechas y rectilíneas y manzanas de viviendas de $20 \mathrm{~m}$ de longitud y anchura variable (Fritz 1995: 90-93 figs. 31-32). Poco antes tuvo lugar una reconstrucción similar en Tell Qasile. En el estrato x de este yacimiento (siglos XI-X a.C.), apoyado sobre los restos de una violenta destrucción, se aprecia una nueva disposición de los edificios que los enmarca ahora en un callejero caracterizado por la presencia de manzanas rectangulares de dimensiones variables (cf. Fritz 1995: 48 fig. 13).

Las fundaciones de apoikíai constituyen un caso diverso. En ellas, no solamente se trata de construir una ciudad ex novo, sino de proceder a su ordenación territorial según los principios que sustentan un determinado proyecto político (La Torre 2011). Se ha argumentado que en muchas ocasiones este proyecto observaba el principio de la isomoiría, es decir, comportaba una repartición equitativa de la tierra entre los colonos (Th. 6.27.1). Este problema, a diferencia de otros, sí que fue afrontado mediante la parcelación del territorio en partes iguales, los oikópeda, que debían ser asignados a los participantes de la aventura colonial, tanto en el interior de la ciudad como en la chora que la rodeaba. Esta fue una de las obligaciones más importantes de entre las que tenía que afrontar el oikistés (Hom. Od. 6.7-11) y que podía, si mal gestionada, hacer fracasar todo el proyecto (Hoepfner y Schwandner 1994: 299). Las necesidades de expansión y propiedad de la tierra surgidas en el mundo griego arcaico exacerbaron así un conflicto político, que los conocimientos geométricos y topográficos entonces existentes en el Mediterráneo oriental podían ayudar a resolver: Städte zu gründen, hieß in jedem Fall, Land zu vermessen (Hoepfner y Schwandner 1994: 1). El modelo conocido por la investigación como ciudad per strigas se impuso así como una solución frecuente para aquellas fundaciones que comportaron movimientos demográficos relativamente amplios, aunque no debemos olvidar que la cantidad real de población efectivamente desplazada en el marco de estas experiencias se limitó frecuentemente a varios centenares de colonos, algunos miles en los casos más poblados. Estas ciudades, cuyos ejemplos más conocidos son Mégara Hiblea, Siracusa, Selinunte o Metaponto (Mertens 2006: 46-49, 63-89), se caracterizaron por sus manzanas estrechas y alargadas ${ }^{9}$ delimitadas por callejones de 2 ó $3 \mathrm{~m}$ de anchura, los stenópoi. Estas insulae estuvieron atravesadas por avenidas, las platéiai, que, con una dirección aproximadamente perpendicular, podían llegar a duplicar o triplicar la anchura de los stenópoi. Frecuentemente se dieron, en la misma ciudad, diversas orientaciones a diversos grupos de manzanas y calles. En estos casos, el ágora, como espacio libre de construcciones, fue el lugar idóneo en donde casar orgánicamente los diversos patrones urbanísticos, como en Selinunte (Mertens 2003: plano 9) o Mégara Hiblea (Gras et alii 2004).

La interpretación que la arqueología colonial ha ofrecido de la diáspora fenicia, como una persecución de intereses exclusivamente comerciales, ha sido criticada en las últimas décadas (González Wagner y Alvar Ezquerra 1989; Domínguez Monedero 2003; Bonnet y Krings 2006: 44) y está siendo superada por la investigación reciente (Gómez Bellard 2003; López Castro 2006; Van Dommelen y Gómez Bellard 2008; Aubet Semmler 2009a: 57-63 y 76-82; López Castro et alii 2010). Sin embargo, tanto la arqueología cartaginesa como la fenicio-punica todavía tienen que superar los límites que le impone un registro arqueológico producido e interpretado por y desde lecturas de la Antigüedad excesivamente helenocéntricas (Bonnet 2005; Fumadó Ortega 2013b: 53-72). Actualmente el registro es solo abundante para el estudio de las necrópolis y, al margen de Cartago, Solunto, Mozia y Beirut, no existen excavaciones de grandes dimensiones en ciudades fenicio-punicas ${ }^{10}$. Si la Arqueología logra algún día colmar estos vacíos, la Historia deberá reconocer a estas sociedades el importante papel que probablemente les corresponde en la formación de la ciudad europea, tanto en sus aspectos físicos como políticos (Gschnitzer 1988: 300-302; Günther 1996: 790-791; Gras 2002: 189-192).

\footnotetext{
${ }^{9}$ Con anchuras que van desde los $25 \mathrm{~m}$ en Casmene hasta los 35 m en Agrigento (cf. Hoepfner y Schwandner 1994: 2-9) y una relación entre longitud y anchura variable, contándose para la época arcaica los casos de Selinunte con 1/6 y de Metaponto con 1/7 (Tréziny 2006: 231).

${ }^{10}$ Problema agravado por la continuada habitación sobre los yacimientos. No obstante, la investigación podrá dar grandes pasos con la publicación y estudio de conjunto de las intervenciones realizadas en las últimas décadas en ciudades como Cádiz, Ibiza, Málaga, por citar algunas de ámbito peninsular (cf. Niveau de Villedary y Mariñas 2010; Ramón Torres 2010; Mora Serrano y Arancibía Román 2010). La continuidad del proyecto dirigido por el catedrático José Luis López Castro en Utica aportará datos imprescindibles para comprender el desarrollo urbano del Mediterráneo central. Por su parte, yacimientos como Toscanos, Kerkouan o Monte Sirai, con sus reducidas dimensiones, lejos de las 20 ha de la Cartago arcaica, no permiten elaborar un discurso integral sobre el espacio urbano en las sociedades fenicio-púnicas.
} 


\section{EL CONTEXTO SOCIOPOLÍTICO DE LOS FUNDADORES DE CARTAGO}

Existen dos mitologías principales sobre la fundación de Cartago: la de Karkhedón y Azoros y la de Elisa-Dido. Ambas son conocidas al menos desde las obras de Filisto de Siracusa ( $F G H$., III, B, 556 F 47), para la primera versión, y de Timeo de Taormina (FGH., III, B, $556 \mathrm{~F} 82$ ), para la segunda ${ }^{11}$. Los dos historiadores sicilianos, de la primera mitad del siglo IV y del siglo III a.C. respectivamente, reelaboraron con objetivos políticos estos relatos (Bonnet 2011), que nos han sido a su vez trasmitidos a través de los filtros culturales del imperio romano (App. Pun. 1; Just. 18.4-6). Sin embargo, ambas mitologías fundacionales contienen elementos fenicios (Bunnens 1979: 128 y 136). Estos indican que dichos relatos no son productos exlcusivamente siciliotas y delatan una verosímil referencia de la tradición púnica, hoy perdida, pero sin duda conocida por los historiadores de Sicilia prerromana.

De estas fuentes se deduce que en el Mediterráneo de época helenística y republicana existía el recuerdo de una expansión fenicia muy antigua, dirigida principalmente desde Tiro (cf. Bunnens 1979). En dicho recuerdo, la expansión no estuvo motivada solo por la búsqueda de comercio y riquezas por parte de los navegantes fenicios (D.S. 5.20.1-4), sino también por las convulsiones políticas y sociales que sufrieron sus ciudades (Sall. Iug. 19). En el marco de estas se podría encuadrar el conflicto relatado en el mito de Elisa, hermana del Rey de Tiro, quien escapa junto a varios senadores y al sacerdote chipriota de Júpiter (Just. 18.4-5.2).

Apenas existen datos, que no sean ex silentio, para reconstruir la estructura social de la primera Cartago. Sin embargo, tanto la gran cantidad y variedad de productos importados desde largas distancias que se han hallado en los estratos del siglo VIII a.C. (Vegas 2002), como las fuentes escritas (Th. 6.2.6), indican que Cartago ya disponía de una importante posición geopolítica y socioeconómica a la llegada de los griegos a Sicilia. Es verosímil, por tanto, que a finales del siglo IX a.C. zarpasen desde Tiro colonos dispuestos a fundar una verdadera comunidad política y religiosa, es decir, una Ciudad Nueva, como el propio nombre

${ }^{11}$ Como ya han puesto de relieve numerosos especialistas, el uso de las fuentes clásicas para la investigación feniciopúnica resulta extremamente arduo por diversos motivos: percepción de lo extranjero, categorización de lo desconocido y desprestigio del enemigo son algunos de los principales para los autores contemporáneos a Cartago, además de las reinterpretaciones, interpolaciones y epítomes de los que han sido objeto durante los siglos posteriores. de Qart Hadasht indica. Dichos colonos procedían de una ciudad-estado que atravesaba desde mediados del siglo $\mathrm{X}$ a.C. un periodo de esplendor. La monarquía tiria disfrutó desde principios del siglo IX a.C. de las condiciones históricas necesarias para poner en marcha una auténtica expansión cultural (Aubet Semmler 2009a: 90-95). Así, se podría afirmar que quienes llegaron a la península cartaginesa para fundar la Ciudad Nueva crecieron y se educaron, durante la primera parte de sus vidas, inscritos en una comunidad de ciudadanos fuertemente consolidada en cuanto tal, con todas las consecuencias políticas que ello implica. ¿Podemos descartar totalmente que este evento haya motivado algunos detalles de los mitos fundacionales reelaborados por los historiadores siciliotas?

Aunque podemos suponer que la aristocracia tiria participó en la empresa a partir de las fuentes clásicas (cf. Huß 1985: 39-43), no parece que se pueda defender la fundación en Cartago de una monarquía. A la elocuente ausencia de cualquier evidencia epigráfica en este sentido (Sznycer 1984: 291-301; Huß 1997: 139-151) cabe añadir el escaso culto oficial que parece haber recibido en Cartago el dios de la realeza tiria, es decir, Melqart (Bonnet 1988: 122 y ss.), pese a la popularidad que siempre mantuvo entre la población (Bonnet 1988: 186). Tampoco se le dedicó ninguna de las cinco colinas que rodeaban a la Nueva Cartago (Plb. 10.10.6-12). Corinne Bonnet (1988: 174) ha propuesto la lectura de la muerte ritualizada de Elisa y de su culto posterior (Sil. 1.81-84), como una explicación mítica del rápido final que halló la monarquía cartaginesa (cf. Tsirkin 1986: 137), si es que efectivamente alguna vez existió. Este proceso podría entenderse como análogo al que parece haber tenido lugar en las colonias griegas arcaicas, en las que, tras la muerte del oikistés, este sufría un proceso de heroización a través del cual, su culto era colectivizado (Malkin 2002: 201-211). De esta forma se pretendía evitar que sus descendientes privatizasen su memoria y aspirasen a heredar su estatus de privilegio, proponiéndose como tiranos o incluso como monarcas.

Si recordamos el modo en que diversos autores griegos, entre los que destaca Aristóteles (Aristot. pol. 2.11.1272b-1273b), elogiaron la constitución cartaginesa (Huß 1985: 458 nota 1; Gschnitzer 1993: 188-191), podemos asumir que el sistema político cartaginés fue percibido por sus contemporáneos helenos, al menos a partir del siglo IV a.C., como una polis (Tsirkin 1986: 129; González Wagner 2006: 105-107). En este sentido, Cartago parece ser diversa a las fundaciones arcaicas de tipo empórico (Niemeyer 2006: 154-159) y próxima, en cambio, a las apoikía: All these features make Carthage structurally 
a case apart in the context of Phoenician expansion: the city was a real apoikia (Niemeyer 2006: 161). Permanece abierta, sin embargo, la cuestión sobre el significado y la interpretación de la primera fase arqueológicamente documentada en el yacimiento, es decir, el periodo previo a la implantación de un diseño colectivo de los espacios urbanos. Será conveniente recordar que en el mito fundacional se mencionan no solo varios intentos constructivos, sino también la formación, previa a dichos tentativos, de una especie de ciudad causada por la llegada de múltiples gentes de procedencias diversas atraídas por las posibilidades de comerciar con los recién llegados (Just. 18.5.11-16). Cuando finalmente se procede a la fundación, con el acuerdo de todas las partes, la extensión de territorio ocupado al menos desde mediados del siglo VIII a.C., aproximadamente 20 ha, supera con creces las 5 ha que, como máximo, alcanzan los emporia arcaicos, siendo la mayoría de ellos mucho menores; la existencia de un mito de fundación o el hecho de que ya en el siglo VI a.C. la ciudad fuese capaz de institucionalizar un estado territorial con ambiciones ultramarinas (Gschnitzer 1993; González Wagner 1994; Quesada Sanz 2009), si bien no necesariamente imperialistas (Domínguez Monedero 2010: 735-759), precediendo en ello a Siracusa (Huß 1985: 57-74), también pueden ser tomados como rasgos significativos del temprano estatus político de la Ciudad Nueva.

Por todo ello, sostengo la oportunidad de entender el nacimiento de Cartago como el traslado de una comunidad política y religiosa que encontró en la implantación de un catastro a mediados del siglo VIII a.C. la solución a una serie de problemas políticos habitualmente asociados a este tipo de ciudades nuevas.

\section{CONCLUSIÓN: UNA PROPUESTA PARA LA FOR- MA DE LA CARTAGO ARCAICA}

Para los colonos recién llegados a la península cartaginesa las prioridades debieron de ser la definición del propio territorio, la elección de los lugares de culto y sacrificio a los dioses, la distribución del espacio edificable, la construcción de las viviendas y la ubicación de las necrópolis, del mismo modo que parece haber sucedido en las apoikíai griegas (Malkin 1987: 336; La Torre 2011: 157-188). Los colonos tirios procedían de una sociedad en la que las habilidades técnicas necesarias para la subdivisión del terreno edificable no solo eran conocidas, sino dominadas con maestría reconocida en toda la región siriopalestina (Aubet Semmler 2009a: 68-69; 2009b). Por ello considero fundamental dirigir la atención futura no ya hacia las habilidades topográficas y organizativas de los colonos tirios, sino hacia los problemas políticos que les impulsaron a disponer su Ciudad Nueva per strigas y no de otro modo.

A continuación voy a presentar una propuesta gráfica sobre la forma urbana de la Cartago arcaica en la que el núcleo de hábitat, aparecerá caracterizado por la presencia de las strigas aplicadas en otras apoikíai en el Mediterráneo central de los siglos VIII-VI a.C. El espacio ocupado por dichas manzanas en esta reconstrucción es de 13 ha, divisibles en unas mil parcelas de un área que oscilaría entre 96 y $72 \mathrm{~m}^{2}$ (v. supra). Se pudo dar así cobijo a los pocos miles de habitantes que, durante los siglos VIII-VII a.C., constituirían la población cartaginesa. Junto al espacio dedicado a las necrópolis y a las áreas de trabajo, la ciudad arcaica pudo haber superado las 20 ha.

Los elementos arqueológicamente demostrados en esta propuesta son los trazos indicados en negro: restos de viviendas, el tramo de muralla documentado en Bir Massouda, las necrópolis arcaicas en las colinas de la Byrsa, de Juno y de Bordj Djedid, la ubicación de los barrios industriales y la línea de costa antigua. Considerando los paralelos sicilianos mencionados, la metrología fenicia y la coincidente orientación de los edificios cartagineses datados con cronologías arcaicas (v. supra), paso a presentar una propuesta global para la forma urbana de la Cartago fenicia (Fig. 3).

Esta estructura urbanística debió de marcar significativamente las posibilidades de expansión de la ciudad durante los siglos siguientes. En efecto, pese a que solo en cinco excavaciones se han hallado en el interior del área propuesta para las strigas restos murarios arcaicos (Fig. 1.6-9, 1.13), otras estructuras arquitectónicas con cronologías posteriores, o fuera de estos márgenes pero con la misma orientación, han sido documentadas hasta en 13 áreas (Fig. 1.1-5, 1.10-12, 1.14-18). Teniendo en cuenta el volumen y la calidad de la información disponible en este yacimiento, considero que la hipótesis presentada en la figura 3 es, actualmente, la más solida para explicar y reconstruir la forma urbana de la Cartago arcaica.

Las colinas que rodean la llanura litoral de Cartago debieron de haber sido ocupadas desde los primeros días de existencia de la ciudad fenicia, quizá por santuarios que solo con el tiempo se fueron fortificando, pero que habrían dado desde el primer momento la seguridad necesaria a sus fieles ciudadanos. Eshmún, Astarté, Melqart y Ba`al Hammón fueron los principales dioses, aunque no los únicos, que viajaron con los primeros colonos tirios para establecerse en estas 


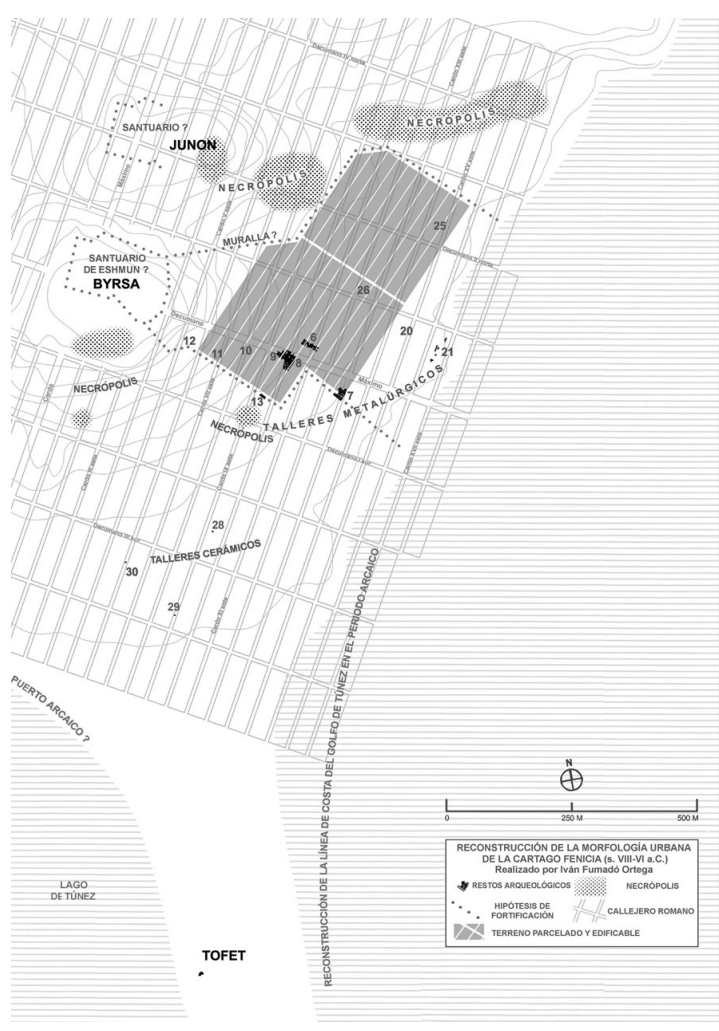

Figura 3. Propuesta de reconstrucción de la morfología urbana de la Cartago fenicia. En negrita figuran los restos arquitectónicos arcaicos y en gris el espacio que debieron de ocupar doce manzanas calculadas según la hipótesis metrológica de la fig. 2. Los números corresponden a los de la fig. 1. Diseñada por el autor.

colinas, quizá aplicando criterios de accesibilidad, seguridad, facilidad para la purificación y epipháneia, del mismo modo que sus contemporáneos griegos (cf. Malkin 1987: 344).

Sin embargo, todo ello no constituye prueba en favor de la hipótesis apuntada por Pierre Cintas, desarrollada por Serge Lancel y tácitamente aceptada por Friedrich Rakob, según la cual se habría instalado en la cima de la Byrsa un primer núcleo de hábitat que, creciendo, habría adoptado una forma en abanico como un tell oriental. Al margen de la ausencia de pruebas arqueológicas de cronología arcaica en este sentido, cabe recordar que los testimonios clásicos que describen una Byrsa rodeada de edificios (Str. 17.3.14-15; Serv. In Aen. 1.421; App. Pun. 130), no se refieren en ningún caso a momentos anteriores a los siglos IV-III a.C. La situación que estos señalan bien podría responder a un fenómeno, acaecido sólo a partir de los siglos IV-III a.C., de saturación del espacio disponible para las construcciones privadas. El aumento de la presión demográfica en la ciudad habría podido llevar a una yuxtaposición de edificaciones desde la zona baja, ocupada desde antiguo, hacia las zonas menos pobladas, es decir, hacia las pendientes más altas de las laderas que rodeaban el casco antiguo. Así, la forma en abanico de las calles que rodearon la Byrsa durante sus últimos siglos púnicos tendría poco que ver con la disposición urbana de Kerkouán o con la de las ciudades del Bronce siriopalestino. Esta morfología sería en cambio el resultado tanto de la orografía de la colina como de la adaptación de las viviendas a los espacios dejados libres por los témene arcaicos y por sus vías de acceso ${ }^{12}$. No sería sorprendente hallar un registro análogo en la colina de Juno, menos interrogada por la arqueología moderna.

El concepto conservador y reductivo de identidad con el que se ha explicado hasta ahora la Historia de Cartago ha llevado a asumir que las sociedades tienen culturas estables y compactas y que los cambios culturales equivalen a pérdidas de identidad (Lancel 1994: 281). Sin pretender infravalorar la importancia que las tradiciones semitas habrían podido llegar a tener en la sociedad cartaginesa, considero que los manuales universitarios actualmente disponibles sobreestiman en sus interpretaciones el valor del origen oriental de los colonos, de tal forma que esta procedencia determina todas las manifestaciones culturales futuras de la ciudad. Así se ha intentado demostrar repetidas veces la existencia en Cartago de elementos típicamente orientales, como una realeza sacra ${ }^{13}$ o una morfología urbana dominada por un palacio-templo en la cima de un tell, en cuyas faldas se apiñarían viviendas mínimamente separadas por caóticos callejones, como un ancestro urbanístico de las medinas musulmanas.

Debemos tener en cuenta una vez más que, tanto durante la Antigüedad, a partir de las guerras contra Siracusa y especialmente contra Roma, como en tiempos modernos (Ferrer Albelda 2003; Bonnet y Krings 2006; Fumadó Ortega en prensa c), la representación de la Cartago fenicia y púnica ha sido constantemente instrumentalizada mediante muy diversos discursos políticos, que le han otorgado siempre el valor del otro, de lo extraño y del enemigo. Esta categorización ha consolidado una representación del pasado cartaginés como algo

\footnotetext{
${ }^{12}$ Este fenómeno encuentra paralelos en algunas ciudades modernas, como Lisboa, en donde las murallas y las puertas del Castelo de São Jorge han determinado los recorridos de ascenso a la colina y, con ellos, la orientación de los edificios que se han ido construyendo sucesivamente en sus laderas.

${ }^{13}$ A pesar de que Serge Lancel (1994: 111-113) es muy cauto a la hora de aceptar todas las atribuciones del difícilmente sostenible (v. supra) Rey de Cartago, cabe señalar que el autor que más cita para referirse a esta cuestión es el polémico defensor de la frágil tesis de Julius Beloch, es decir, Gilbert Charles Picard.
} 
profundamente ajeno la cultura occidental. Sin embargo, dicha representación no se corresponde con los datos ofrecidos ni por las fuentes clásicas ni por la arqueología, cuando estos son adecuadamente interrogados (Bonnet 2005). Por todo ello, considero que se debe desechar la hipótesis de la Byrsa-tell y situar en el centro del debate los motivos políticos por los que la Cartago arcaica se configuró como una ciudad per strigas.

\section{BIBLIOGRAFIA}

Aubet Semmler, M. E. 2009a: Tiro y las colonias fenicias de Occidente, Barcelona.

Aubet Semmler, M. E. 2009b: "Byblos y Tiro. Desarrollo y reestructuración urbanísticas en Fenicia", S. Helas y D. Marzoli (eds.), Phönizisches und Punisches Städtewesen, Iberia Archaeologica 13, Internazionale Tagung in Rom, DAI, Febrero 2007, Mainz, 21-37.

Babelon, E. 1896: Carthage, Paris.

Baradez, J. 1958: "Nouvelles recherches sur les ports antiques de Carthage", Karthago 9, 45-79.

Barresi, P. 2007: Metrologia punica, Lugano.

Ben Younès, H. 1995: “Tunisie”, V. Krings (ed.), La civilisation phénicienne et punique: manuel de recherche, Leiden, 796-827.

Bénichou-Safar, H. 1976: "Carte des nécropoles puniques de Carthage", Karthago 17, 1-35.

Bénichou-Safar, H. 1982: Les tombes puniques de Carthage, Paris.

Bénichou-Safar, H. 1995: "Les fouilles du tophet de Salammbô à Carthage, I", Antiquités Africaines 31, 81-200.

Beulé, Ch. E. 1861: Fouilles à Carthage, Paris.

Bonnet, C. 1988: Melqart. Cultes et mythes de l'Héraclès tyrien en Mèditerranèe. Studia Phoenicia 8, Leuven.

Bonnet, C. 2005: “Carthage, 'l'autre nation' dans l'historiographie ancienne et moderne", Anabases 1, 139-160.

Bonnet, C. 2011: "Le destin fémenin de Carthage", Pallas 85, 19-29.

Bonnet, C. y Krings, V. 2006: "Les Phéniciens, Carthage et nous: histoire et representations", J. P. Vita y J. A. Zamora (eds.), Nuevas perspectives I: la investigación fenicia y púnica, Cuadernos de Arqueología Mediterránea 13, 37-47.

Bunnens, G. 1979: L'expansion phénicienne en Méditerranée, Roma.

Cagnat, R. 1909: Carthage, Timbad, Tébessa, Paris.

Cintas, P. 1970-1976: Manuel d'Archéologie punique, Paris, 2 vols.
Chelbi, F. 1984: "Découverte d'un habitat punique sur le flanc sud-est de la colline Byrsa", Bulletin Archéologique du Comité des Travaux Historiques et Scientifiques 17-b (n.s.), 21-34.

Chelbi, F. 2004: "Tunesische Forschungen in Karthago", Hannibal ad Portas, Macht und Reichtum Karthagos, Karlsruhe, 52-59.

Chelbi, F., Maraoui-Telmini, B. y Docter, R. F. 2007: "Bilan des fouilles du terrain de Bir Massouda (Carthage): campagnes 2002 à 2004”, Africa 3 (ns), 207-225.

Clermont-Gennau, M. 1896: "Sur l'utilité et l'urgence qu'il y aurait à dresser un plan de Carthage et de ses environs", Comptes Rendus de l'Académie des Inscriptions et Belles- Lettres 24 ( $4^{\mathrm{a}}$ s.), 439-444.

Davis, N. 1861: Carthage and her remains, London.

Debergh, J. 1991: "Cartes archéologiques et topographiques de Carthage: une suggestion", II Congresso Internazionale di Studi Fenici e Punici, Roma 1987, 813-816.

Delattre, A. L. 1898: "Carthage. Découvertes de tombes puniques, I. La colline de Saint- Louis", Bulletin Société de Géographie et d'Archéologie de la province d'Oran 20, 140-150.

Dietler, M. 2005: "The Archaeology of Colonization and the Colonization of Archaeology: Theoretical Challenges from an Ancient Mediterranean Colonial Encounter", G. J. Stein (ed.), The Archaeology of Colonial Encounters, Santa Fe, 33-69.

Docter, R. F. 2003: "The topography of archaic Carthage", Talanta 34-35, 113-134.

Docter R. F., Chelbi, F. y Maraoui-Telmini, B. 2003: "Preliminary report on the first bilateral excavations of Ghent University and the Institut National du Patrimoine (2002-2003)", Babesch 78, 43-70.

Docter R. F., Chelbi, F. y Maraoui-Telmini, B. 2006: "Second preliminary report on the bilateral excavations of Ghent University and the Institut National du Patrimoine (2003- 04)", Babesch 81, 37-90.

Domínguez Monedero, A. J. 2003: "Fenicios y griegos en Occidente. Modelos de asentamiento e interacción", XVII Jornadas de Arqueología FenicioPúnica, Eivissa 2002, 19-60.

Domínguez Monedero, A. J. 2010: "Cartago y Sicilia durante los siglos VI y V a.C.” E. Ferrer Albelda (ed.), Los púnicos de Iberia: Proyectos, revisiones, síntesis, Mainake 32-1, 735-759.

Drappier, L. 1911: "Nécropole punique du Théâtre de Carthage", Revue Tunisienne 18, 254-260.

Duval, R. 1950: "Mise au jour de l'enceinte extérieure de la Carthage punique", Comptes Rendus de l'Académie des Inscriptions et Belles-Lettres, 53-59. 
Duval, N. 1972: "Études d'architecture chrétienne nordafricaine", Mélanges de l'École Française de Rome (Antiquité) 94 (2), 1071-1172.

Ellis, P. 1988: "Carthage, Sewer Project", CEDAC 9, 6-38.

Ellis, P. 1989: “Archéologie de sauvetage. Fouilles britanniques", CEDAC 10, 12-13.

Ennabli, A. 1992: Pour sauver Carthage, Paris.

Ennabli, L. 1997: Carthage, métropole chrétienne du IV-VII siècle, Paris.

Fantar, M. H. 1993: Carthage, approche d'une civilisation, Tunis, 2 vols.

Ferrer Albelda, E. 2003: "Gloria y ruina de la Iberia Cartaginesa. Imágenes del poder en la historiografía española", Cuadernos de Prehistoria y Arqueología de la Universidad Autónoma de Madrid 28-29, 7-21.

Ferron, J. y Pinard, M. 1955: "Fouilles de Byrsa 195354", Cahiers de Byrsa 5, 31-264.

Ferron, J. y Pinard, M. 1961: "Les fouilles de Byrsa", Cahiers de Byrsa 9, 77-170.

Freed, J. 2001: "Bibliography of publications by Alfred-Louis Delattre (1850-1932)", CEDAC 20, 3-60.

Fritz, V. 1995: The city in ancient Israel, Sheffield.

Fumadó Ortega, I. 2009: Cartago: Historia de la investigación, Madrid.

Fumadó Ortega, I. 2010: "Cartago: usos del suelo en la ciudad fenicia y púnica", Archivo Español de Arqueología 83, 9-26.

Fumadó Ortega, I. 2013a: Cartago fenicio-púnica: Arqueología de la forma urbana, Sevilla.

Fumadó Ortega, I. 2013b: "Colonial representations and Carthaginian Archaeology", Oxford Journal of Archaeology 32 (1): 53-72.

Fumadó Ortega, I. (en prensa): "Las excavaciones en Cartago de Salomon Reinach y Ernest Babelon. Documentos para el estudio de la morfología urbana”, VIIe Congrès International des Études Phéniciennes et Puniques, Hammamet 2009.

Gauckler, P. 1915: Nécropoles puniques de Carthage, Picard, Paris, 2 vols.

George, A. R. 2008: "Die babylonischen topographischen Texte", Babylon - Wahrheit, Katalog der Ausstellung, 405-412.

Gerner Hansen, C. 2002: Carthage: results of the Swedish Excavation, $4^{\circ}$, LIV: I.

González Wagner, C. 1994: "Guerra, ejército y comunidad cívica en Cartago", Homenaje al profesor Presedo, Sevilla, 825-835.

González Wagner, C. 2006: “Ciudad y ciudadanía en la Cartago púnica”, F. Marco Simón, F. Pina Polo y J. Remesal Rodríguez (ed.), Repúblicas y ciudadanos: modelos de participación cívica en el mundo antiguo, Barcelona, 103-113.

González Wagner, C. y Alvar Ezquerra, J. 1989: “Los fenicios en occidente. La colonización agrícola", Rivista di Studi Fenici 17, 61-102.

Gómez Bellard, C. 2003: Ecohistoria del paisaje agrario. La agricultura fenicio-púnica en el Mediterráneo, II Coloquio del Centro de Estudios Fenicios y Púnicos, Valencia.

Gras, M. 2002: "Périples culturels entre Carthage, la Grèce et la Sicile au VIIIè siècle av. J. C.”, Ch. Müller y F. Prost (eds.), Identités et cultures dans le monde méditerranéen antique, Paris, 183-198.

Gras, M., Tréziny, H., Broise, H., Pelagatti, P. y Voza, G. 2004: Mégara Hyblaea, V. La ville archaique: l'espace urbain d'une cité grecque de Sicilie orientale, Roma.

Greco, E. y Torelli, M. 1983: Storia dell'Urbanistica. Il mondo greco, Bari.

Gschnitzer, F. 1988: "Die Stellung der Polis in der politischen entwicklung des Altertums", Oriens Antiquus 27, 287-302.

Gschnitzer, F. 1993: "Phoinikisch-Karthagisches Verfassungsdenken”, K. Raablauf (ed.), Anfänge politischen Denkens in der Antike. Die nahöstliche Kulturen und die Griechen, München, 187-198.

Günther, L. M. 1996: "Die Phönizier und die Entstehung der griechischen, Polis”, E. Acquaro, (ed.), Alle soglie della classicità. Il Mediterraneo tra tradizione e innovazione. Studi in onore di Sabatino Moscati, Pisa - Roma, 789-799.

Hoepfner, W. y Schwandner, E. L. 1994: Haus und Stadt im Klassischen Griechenland, Berlin.

Humphrey, J. H. 1978: Excavations at Carthage 1975, II, University of Michigan, Ann Arbor.

Hurst, H. 1975: "Excavations at Carthage 1974. First interim report", Antiquaries Journal 55, 11-40.

Hurst, H. 1992: "L'ilôt de l'Amirauté, le port circulaire et l'avenue Bourguiba", A. Ennabli (ed.), Pour Sauver Carthage, Paris, 79-94.

Hurst, H. 1999: The Sanctuary of Tanit at Carthage in the Roman Period, Journal of Roman Archaeology, suppl. 30, Portsmouth, Rhode Island.

Hurst, H. y Roskams, S. P. 1984: Excavations at Carthage, the British Mission, I-1, Oxford.

Huß, W. 1985: Geschichte der Karthager, HAW, 3 - 8, München.

Huß, W. 1997: "Noch einmal: die karthagischen Könige", Rivista di Studi Fenici 25, 139-151.

Kelsey, F. W. 1926: Excavations at Carthage, New York.

Kemp, B. J. 1992: El Antiguo Egipto. Anatomía de una civilización, Barcelona. 
Kempinski, A. 1989: Megiddo. A city-state and royal centre in south Israel, Meckenheim.

Kepinski-Lecomte, C. 1996: "Spatial occupation of a new town: Haradum (Iraqi Middle Euphrates, 18th-17th centuries BC.)", K. R. Veenhof (ed.), Houses and households in ancient Mesopotamia, Istambul 1993, Leiden, 191-196.

La Torre, G. F. 2011: Sicilia e Magna Grecia. Archeologia della colonizzazione greca d'Occidente, Roma - Bari.

Ladjimi Sebaï, L. 2003: "Byrsa à l'époque punique. Identification d'un site", Actes du VIII Colloque International sur l'Histoire et l'archéologie de l'Afrique du Nord, Tabarka 2000, 125-138.

Lancel, S. 1979-1982: Byrsa, I-II, Roma.

Lancel, S. 1984: "Remarques sur la topographie urbaine de la Carthage punique", Bulletin Archéologique du Comité des Travaux Historiques et Scientifiques 17-b (n.s.), 35-54.

Lancel, S. 1989a: "L'encinte périurbaine de Carthage lors de la troisième guerre punique: réalités et hypothèses", Lipinski, E. y Devijver, H. (eds.), Punic wars, Studia Phoenicia 10, 251-278.

Lancel, S. 1989b: "Une fouille ancienne de P. Cintas à l'ouest des Thermes d'Antonin et la topographie du secteur nord-est de la Carthage punique", Bulletin Archéologique du Comité des Travaux Historiques et Scientifiques 20-21 (n.s.), 19841985, 35-52.

Lancel, S. 1990: "Problèmes d'urbanisme de la Carthage punique, à la lumière des fouilles anciennes et rècentes", IV Coloque International Histoire et Archéologie de l'Afrique du Nord, Strasbourg 1988, 9-30.

Lancel, S. 1994 [1992]: Cartago, Barcelona.

Lancel, S. 2000: "Carthage: de la colonie tyrienne à la mégapole hellénistique", C. Nicolet, R. Ilbert, y J. Ch. Depaule (eds.), Mégapoles méditerranéennes: géographie urbaine rétrospective, París, 506-534.

Lancel, S. 2002: "Mission archéologique suédoise. Fouille d'un tombe punique: 7 au 17 juin 1980", C. Gerner Hansen (ed.), Carthage: Results of the Swedish Excavation, LIV,I, 19-22; 121-122.

Lapeyre, G. G. y Pellegrin, A. 1950: Carthage latine et chrétienne, Paris.

López Castro, J. L. 2006: "Los fenicios occidentales: de colonias a ciudades", Arqueo Mediterrània 9, 43-51.

López Castro, J. L., Martínez Hanmüller, V. y Pardo Barrionuevo, C. A. 2010: "La ciudad de Baria y su territorio”, E. Ferrer Albelda (ed.), Los púnicos de Iberia: Proyectos, revisiones, síntesis, Mainake 32 (1), 109-132.
Malkin, I. 1987: "La place des dieux dans la cité des hommes. Le découpage des aires sacrées dans les colonies grecques", Revue de l'histoire des religions 204 (4), 331-352.

Malkin, I. 2002: "Exploring the concept of "Fundation": a visit to Megara Hyblaia", V. B. Gorman y E. W. Robinson (eds.), Oikistes. Studies in constitutions, colonies, and military power in the ancient world. Offered in honor of A. J. Graham, Köln, 195-228.

Marchand, S. 1996: Down from Olympus. Archaeology and philhellenism in Germany, 1750-1970, Princeton.

Merlin, A. 1909: "Note sur les fouilles exécutées en 1908 dans la région des ports de Carthage", Bulletin Archéologique du Comité des Travaux Historiques et Scientifiques, 51-53.

Merlin, A. 1912: "Fouilles dans l'îlot de l'Amiral à Carthage", Comptes Rendus de l'Académie des Inscriptions et Belles-Lettres, 277-286.

Merlin, A. 1918: "Fouilles de tombeaux puniques à Carthage", Bulletin Archéologique du Comité des Travaux Historiques et Scientifiques, 288-334.

Mertens, D. 2006: Città e monumenti dei Greci d'Occidente: dalla colonizzazione alla crisi di fine $V$ secolo a.C., Roma.

Mertens, D. 2003: Selinus, I. Die Stadt und ihre Mauern, Mainz.

Mora Serrano, B. y Arancibía Román, A. 2010: “La Bahía de Málaga en los periodos púnico y romanorepublicano: viejos problemas y nuevos datos", E. Ferrer Albelda (ed.), Los púnicos de Iberia: proyectos, revisiones, síntesis, Mainake 32 (2), 813-836.

Niemeyer, H. G. 2006: "The Phoenicians in the Mediterranean. Between Expansion and Colonisation: A non-Greek Model of Overseas Settlement and Presence", G. Tsetskhladze (ed.) Greek Colonisation. An account of Greek Colonies and other Settlements Overseas, Leiden, 143-168.

Niemeyer, H. G., Docter, R. F., Schmidt, K. y Bechtold, B. 2007: Karthago. Die Ergebnisse der hamburger Grabung unter dem Decumanus Maximus, Mainz.

Niveau de Villedary y Mariñas, A. M. 2010: "Deconstruyendo paradigmas. Una (re)visión historiográfica crítica al modelo interpretativo tradicional del Cádiz fenicio-púnico a la luz de los nuevos datos", E. Ferrer Albelda (ed.), Los púnicos de Iberia: proyectos, revisiones, síntesis, Mainake 32 (2), 619-671.

Panero, E. 2008: La Maalga e i Porti Punici di Cartagine, Firenze. 
Paskoff, R., Hurst, H. y Rakob, F. 1985: "Position du niveau de la mer et déplacement de la ligne du rivage à Carthage", Comptes Rendus de la Academie des Seances de Paris 300, 2-13, 613-618.

Poinssot, L. y Lantier, R. 1927: "Fouilles à Carthage", Bulletin Archéologique du Comité des Travaux Historiques et Scientifiques, 437-474.

Quesada Sanz, F. 2009: "En torno a las instituciones militares cartaginesas", XXIII Jornadas de Arqueología Fenicio-Púnica, Eivissa 2008, 143-172.

Rakob, F. 1984: "Deutsche Ausgrabungen in Karthago. Die punischen Befunde", Römische Mitteilungen 91, 1-15.

Rakob, F. 1985: "Carthage punique: fouilles et prospections archéologiques de la mission allemande", Revue des Études Phéniciennes-Puniques et des Antiquités Libyques 1, 133- 156.

Rakob, F. 1987: "Zur Siedlungstopographie des punischen Karthago", Römische Mitteilungen 94, 333-349.

Rakob, F. 1989: "Karthago, die frühe Siedlung”, R̈̈mische Mitteilungen 96, 155-208.

Rakob, F. 1991: "Ein punisches Heiligtum in Karthago und sein römischer Nachfolgebau", Römische Mitteilungen 98, 33-80.

Rakob, F. 1992: "L'habitat ancien et le système urbanistique", A. Ennabli (ed.), Pour Sauver Carthage, Paris, 29-37.

Rakob, F. 1995: "Forschungen im Stadtzentrum von Karthago", Römische Mitteilungen 102, 413-474.

Rakob, F. 2002: "Cartago. La topografía de la ciudad púnica. Nuevas investigaciones", M. Vegas (ed.), Cartago fenicio-púnica. Las excavaciones alemanas en Cartago (1975-1997), Cuadernos de Arqueología Mediterránea 4, 14-46.

Rakob, F. 1991-1999: Karthago I-III. Die deutschen Ausgrabungen in Karthago, Mainz.

Ramón Torres, J. 2010: "La ciudad púnica de Ibiza: estado de la cuestión desde una perspectiva historico-arqueológica actual", E. Ferrer Albelda (ed.), Los púnicos de Iberia: proyectos, revisiones, sintesis, Mainake 32 (2), 837-866.

Reinach, S. y Babelon, M. 1886: "Recherches archéologiques en Tunisie (1883-1884)", Bulletin Archéologique du Comité des Travaux Historiques et Scientifiques, 3-78.

Renault, J. 1913: Cahiers d'Archéologie Tunisienne I. Saïd, E. W. 2003 [1978]: Orientalism, London. Sainte-Marie, É. 1884: Mission à Carthage, Paris.
Saumagne, Ch. 1929: "Notes de topographie carthaginoise", Bulletin Archéologique du Comité des Travaux Historiques et Scientifiques, 629-664.

Saumagne, Ch. 1933: "Notes de topographie carthaginoise", Bulletin Archéologique du Comité des Travaux Historiques et Scientifiques, 62-73; 77-90; 325-330; 641-660.

Schaeffer, C. F. A. y Courtois, J. C. 1971: Alasia I, Paris.

Spatafora, F. 2009: "Dagli emporia fenici alle città puniche: Elementi di continuità e discontinuità nell'organizzazione urbanistica di Palermo e Solunto", S. Helas, S. y D. Marzoli (eds.), Phönizisches und Punisches Städtewesen, Iberia Archaeologica 13, Internazionale Tagung in Rom, DAI, Febrero 2007, Mainz, 219-239.

Stevens, S. 1993: Bir el Knissia at Carthage, Journal of Roman Archaeology, suppl. 8, Portsmouth, RI.

Sznycer, M. 1984: "Le problème de la royauté dans le monde punique", Bulletin Archéologique du Comité des Travaux Historiques et Scientifiques 17-b, 1981, 291-301.

Tissot, Ch. 1884: Géographie comparée de la province romaine d'Afrique, Imprimerie Nationale, I, Paris.

Tlatli, S. E. 1978: La Carthage punique. Étude urbaine, la ville, ses fonctions, son rayonnement, Paris.

Tréziny, H. 2006: 'L'urbanisme archaïque des villes ioniennes: un point de vue occidental", Revue des Études Anciens 108, 225-248.

Tsirkin, J. B. 1986: "Carthage and the problem of the polis", Rivista di Studi Fenici 14, 129-141.

Van Dommelen, P. 1998: On colonial grounds: a comparative study of colonialism and rural settlement in first millennium BC west central Sardinia, Leiden.

Van Dommelen, P. y Gómez Bellard, C. 2008: Rural Landscapes of the Punic World, London.

Vegas, M. 2002: "La cerámica de importación en Cartago durante el periodo arcaico", M. Vegas (ed.), Cartago fenicio-púnica. Las excavaciones alemanas en Cartago (1975-1997), Cuadernos de Arqueología Mediterránea 4, 133-145.

Vella, N. 1996: "Elusive Phoenicians", Antiquity 70 (268), 245-250.

Vernaz, J. 1887: "Notes sur les fouilles de Carthage (1884-85)", Revue Archéologique 10 (3 ${ }^{\mathrm{a}}$ s.) 1887, 11-27; 151-170.

Yorke, R. A. y Little, J. H. 1975: “Offshore survey at Carthage 1973", The International Journal of Nautical Archaeology 4, 85-101. 